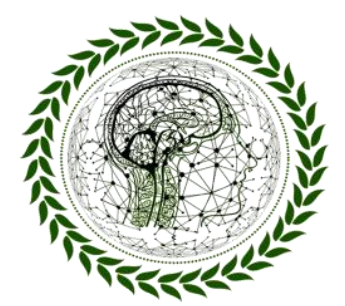

PhI Scientific Review

ISSN 2676 - 0444

Submetido em: 04/12/2021 | Aceito em: 07/12/2021 | Publicado em: 16/12/2021 | Artigo

\title{
TÉTANO EM EQUINOS: UMA REVISÃO NARRATIVA
}

Rodrigo Alberto Peixoto Rodrigues de Souza ${ }^{1}$

\begin{abstract}
Resumo: $\mathrm{O}$ tétano é uma doença grave que pode levar o animal a óbito, sendo provocada pela bactéria anaeróbica Clostridium tetani, que por sua vez libera toxinas que agem no sistema nervoso do animal, causando contração dos músculos, espasmos musculares contínuos, hiperexcitabilidade, entre outros problemas. O trabalho em questão objetiva elaborar uma revisão de literatura sobre o tétano em equinos, abrangendo aspectos relativos à epidemiologia, lesões, sintomas, tratamento e à profilaxia. A metodologia trata-se de um estudo descritivo revisional, verificando-se artigos científicos, teses, dissertações e livros publicados nos últimos 20 anos. Sendo assim, pode-se verificar que métodos de controle e medidas profiláticas podem reduzir significativamente o número de casos clínicos, bem como os prejuízos dos criadores em decorrência da possível morte do animal. Assim, recomendam-se cuidados especiais com os equinos, como, por exemplo, assistência veterinária, vacinação, higienização do local e dos instrumentos usados no manejo e em cirurgias.
\end{abstract}

Palavras-chave: Tétano; equinos; epidemiologia; tratamento.

\section{TETANUS IN EQUINES: A NARRATIVE REVIEW}

\begin{abstract}
Tetanus is a serious disease that can lead to death and is caused by the anaerobic bacteria Clostridium tetani, which in turn releases toxins that act on the animal's nervous system, causing muscle contraction, continuous muscle spasms, hyperexcitability, among other problems. The work in question aims to prepare a literature review on tetanus in horses, covering aspects related to epidemiology, injuries, symptoms, treatment and prophylaxis. The methodology is a descriptive, revisional study, verifying scientific articles, theses, dissertations and books published in the last 20 years. Thus, it can be seen that control methods and prophylactic measures can significantly reduce the number of clinical cases, as well as the losses to breeders due to the possible death of the animal. Thus, special care with horses is recommended, such as, for example, veterinary assistance, vaccination, cleaning of the site and of the instruments used in handling and in surgeries.
\end{abstract}

Keywords: Tetanus; horses; epidemiology; treatment.

${ }^{1}$ Orcid: https://orcid.org/0000-0001-5844-1931

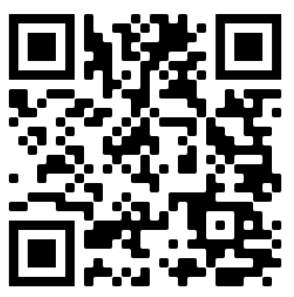

http://www.revistaphd.periodikos.com.br

V. 01, N $\mathrm{N}^{\mathrm{0}}$ 07, dezembro de 2021

DOI: $10.53497 /$ phdsr1n7-002

Todos os direitos reservados( 


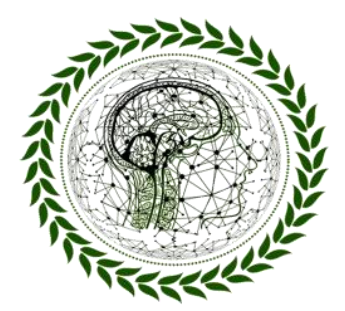

\section{PhD Scientific Review}

ISSN 2676 - 0444

\section{INTRODUÇÃO}

No Brasil, a equinocultura movimenta, anualmente, $\mathrm{R} \$ 16,15$ bilhões e é responsável por três milhões de postos de trabalho, o que dimensiona a importância econômica e social do cavalo no país. Essa criação ganha enorme interesse, visto que o cavalo pode ser utilizado em diversas atividades, como tração e transporte, em segurança pública e até no tratamento de doenças humanas. Nesse cenário, há, inclusive, um programa específico para prevenir, controlar ou erradicar doenças em equinos - o Programa Nacional de Sanidade dos Equídeos - PNSE (MAPA, 2016). Cabe pontuar que todas as espécies de animais de interesse zootécnico são sensíveis, contudo, ocorre variação de susceptibilidade, sendo os equinos os mais sensíveis.

Em relação aos casos de doenças em equinos, observa-se que o tétano consiste em uma toxi-infecção de grande relevância na clínica veterinária, em decorrência da elevada taxa de mortalidade e do longo período de convalescença (PEREIRA et al., 2019).

Zappa e Francisco (2021) explicam que as clostridioses acometem diversas espécies animais de produção e selvagens, salientando que, nos primeiros, os clostridios assumem maior importância por atuarem como agentes primários da doença.

Quanto à caracterização do tétano, trata-se de uma enfermidade tóxica infecciosa, que age por meio de toxinas produzidas pelo Clostridium tetani, microrganismo de distribuição mundial, gram-positivo, encontrado sob a forma vegetativa ou esporulada, conforme as condições de tensão de oxigênio no ambiente (ZAPPA; FRANCISCO, 2021).

Em equinos, a vacinação contra o tétano não é procedimento padrão, o que eleva a mortalidade para 59\% a 80\% nos casos de animais acometidos pela doença. Por essa razão, acredita-se que a profilaxia e a prevenção são os métodos mais eficazes para se evitar a patologia estudada (PEDROSO et al., 2012).

Neste artigo, objetiva-se descrever as características principais do tétano em equinos, a partir do relato de epidemiologia, prognóstico e diagnóstico, conforme literatura atualizada que aborda a temática. Adicionalmente, selecionam-se os métodos de tratamento mais eficazes para o 


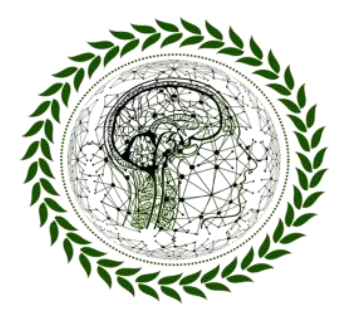

\title{
PhI Scientific Review \\ ISSN 2676 - 0444
}

controle e a eliminação da referida patologia, sob a hipótese de que a clínica do tétano em equinos apresenta resultados satisfatórios, quando no início da sintomatologia.

Como metodologia, propõe-se desenvolver uma revisão atualizada sobre o tétano em equinos, abrangendo aspectos relativos a epidemiologia, lesões, sintomas, tratamento e profilaxia, por meio de pesquisa em bases de dados eletrônicas (PUBVET, PEBMED e IBVET), verificando-se artigos científicos, teses, dissertações e livros publicados nos últimos 20 anos.

\section{REFERENCIAL TEÓRICO}

São necessários cuidados especiais mediante enfermidades que podem levar o equino à morte, a exemplo do tétano. Inicialmente, aborda-se a epidemiologia dessa enfermidade, para, depois, serem apresentadas as possibilidades de prevenção e de tratamento. A doença é relatada em todos os países, pois possui como reservatório do agente o solo contaminado por fezes de animas, sendo mais comum em áreas estreitamente assentadas sob cultivo intensivo (MEGID et al., 2015).

Avante et al. (2013) relacionam a doença aos riscos ambientais, sem o acometimento epidêmico, embora seja uma causa importante de morbimortalidade em países em desenvolvimento e em locais onde não é hábito realizar a vacinação dos animais. Sua taxa de letalidade é variável, podendo chegar a 80\% em equinos.

Zappa e Francisco (2021, s. p.) postulam que

\begin{abstract}
O tétano é causado pela neurotoxina tetanoespasmina, produzida pela forma vegetativa do Clostridium tetani, que se implanta em ferimentos com condições anaeróbicas adequadas para sua multiplicação e, portanto, para a elaboração da toxina responsável pelas manifestações clínicas da doença. Os esporos do C. tetani são extremamente resistentes, permanecendo viáveis ao sol por 12 dias e por muitos anos à sombra.
\end{abstract}

No organismo, o C. tetani libera as toxinas tetanolisina (promove a disseminação da infecção, à medida que aumenta a quantidade de necrose tissular local) e tetanospasmina (responsável pelo desencadeamento dos sinais do tétano) e tetanolisina. Após a ativação dessas 


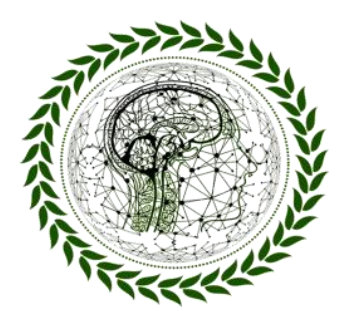

\section{PhI Scientific Review \\ ISSN 2676 - 0444}

substâncias, a cadeia leve age no citoplasma da célula nervosa, quebrando as proteínas celulares e impedindo a liberação dos neurotransmissores modulatórios (PEREIRA et al., 2019).

Nos dizeres de Lima, Patrício e Farias (2013, p. 9),

A tetanolisina que é responsável por ampliar a necrose do tecido local; toxina não espasmogenica que é responsável por fenômenos como a hiperestimulação do sistema nervoso, e; a toxina tetanospasmina que é uma exotoxina que se difunde do local de sua produção até o sistema vascular, espalhando-se entre as placas motoras, interferindo na liberação dos neurotransmissores provocando hipertonia e espasmos musculares.

Segundo Pedroso et al. (2012), solos contaminados por matérias fecais e regiões mais quentes são mais propícios aos esporos de C. tetani, e tal ocorrência também está associada a algumas práticas de manejo, tais como castrações, colocação de brincos ou vacinações. Com menor frequência, a doença pode estar relacionada a infecções pós-operatórias, uterinas ou umbilicais.

De igual modo, Pereira et al. (2019) relatam que a infecção e o surgimento dos sinais clínicos da doença dependem se uma porta de entrada, como um ferimento, ou contato direto com secreções de outros animais já infectados. Zappa e Francisco (2021) confirmam que os casos naturais advêm de infecções profundas e perfurantes, que favorecem a anaerobiose, e em feridas purulentas, uma vez que os germes piogênicos consomem oxigênio, possibilitando o ambiente favorável à proliferação do C. tetani.

Quanto à manifestação clínica do tétano, é necessário ferimento ou solução de continuidade que permita a admissão da bactéria, e o diagnóstico é baseado em sinais clínicos característicos, bem como no histórico de trauma, tosquia, castração ou qualquer outro manejo que sirva como porta de entrada para o agente, não havendo qualquer dificuldade em diferenciála de outros estados tetaniformes (ZAPPA; FRANCISCO, 2021).

Os sintomas característicos do tétano, em equinos, são elencados por Silva et al. (2010): espasticidade muscular, causando movimentos rígidos dos membros ao caminhar; dispneia e dificuldade na mastigação e na deglutição de alimentos; ereção e imobilidade de orelhas; distensão da cabeça; elevação da cauda; podendo, ainda, haver outros sintomas característicos, como a 


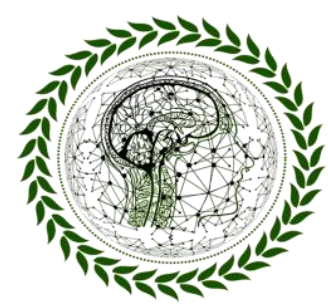

PhI Scientific Review

ISSN 2676 - 0444

hiperestesia e o prolapso da terceira pálpebra. Nos casos mais graves, os equinos apresentam postura de cavalete, dispneia grave, impossibilidade de ingerir alimentos, rigidez do pescoço, sudorese e decúbito. Em geral, a morte ocorre por asfixia após a paralisia dos músculos respiratórios.

Zappa e Francisco (2021) aduzem que a absorção da toxina provoca rigidez muscular localizada, começando próxima à região da ferida e nos músculos de maior atividade como o masseter e pescoço; já a rigidez generalizada ocorre tardiamente, a partir de evidentes espasmos tônicos e hiperestesia. Em geral, a temperatura corpórea do animal permanece elevada, podendo exceder mais que $4{ }^{\circ} \mathrm{C}$ acima da normalidade, antes do óbito.

\section{METODOLOGIA}

Trata-se de um estudo descritivo revisional, verificando-se artigos científicos, teses, dissertações e livros publicados nos últimos 20 anos.

\section{RESULTADOS E DISCUSSÃO}

Como tratamento, no Quadro 1, a seguir, apresentam-se as propostas encontradas na literatura pertinente. 


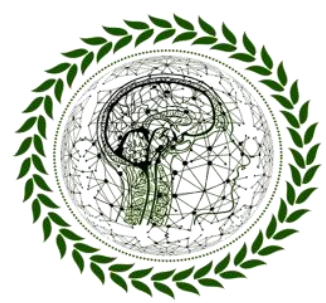

PhI Scientilic Review

ISSN 2676 - 1444

Quadro 1 - Opções de tratamento contra o tétano em equinos

\begin{tabular}{|l|l|l|}
\hline TRATAMENTO & MODO DE AÇÃO & POSOLOGIA \\
\hline Antitoxina Tetânica (TAT) & $\begin{array}{l}\text { Neutraliza as toxinas, através } \\
\text { da eliminação da bactéria } \\
\text { causadora do tétano }\end{array}$ & $\begin{array}{l}\text { Entre 5.000 UI e 50.000 UI, } \\
\text { por via intravenosa, } \\
\text { intramuscular ou subcutânea. }\end{array}$ \\
\hline Penicilina & $\begin{array}{l}\text { Elimina a bactéria - interfere } \\
\text { na síntese da parede celular } \\
\text { bacteriana }\end{array}$ & $\begin{array}{l}20.000 \text { a } 40.000 \text { UI } \backslash \text { KG via } \\
\text { intramuscular, a cada } 48 \text { h, } \\
\text { por 20 dias (no total de dez } \\
\text { aplicações). }\end{array}$ \\
\hline $\begin{array}{l}\text { Soro fisiológico e Soro } \\
\text { vitaminado }\end{array}$ & $\begin{array}{l}\text { Faz a correção do equilíbrio } \\
\text { hidroelétrico e energético. }\end{array}$ & $\begin{array}{l}\text { Sem recomendação específica } \\
- \text { ideal até o animal voltar a } \\
\text { comer sozinho }\end{array}$ \\
\hline Acepromazina & $\begin{array}{l}\text { Atua nas dores musculares do } \\
\text { animal, servindo como } \\
\text { relaxante. }\end{array}$ & $\begin{array}{l}0,5 \text { mL para cada 100 kg, uma } \\
\text { vez ao dia. }\end{array}$ \\
\hline $\begin{array}{l}\text { Diazepam e Xilazina } \\
\text { Atua nas dores musculares do } \\
\text { animal, servindo como } \\
\text { relaxante, em casos de cavalos } \\
\text { refratários aos tranquilizantes } \\
\text { da fenotiazina. }\end{array}$ & $\begin{array}{l}(0,01-0,4 \text { mg/kg) e xilazina } \\
(0,5 \text { - 1,0 mg/kg), por via } \\
\text { intravenosa ou intramuscular. }\end{array}$ \\
\hline
\end{tabular}

Fonte: Autoria própria (2021).

Como explicitado acima, sugere-se a neutralização das toxinas, através da eliminação da bactéria causadora do tétano (AVANTE et al., 2016). Para o controle de espasmos musculares, é necessário manter a alimentação e a hidratação adequadas. Ainda, recomenda-se cama alta, ausência de barulhos e controle da claridade para reduzir o estresse do animal. 


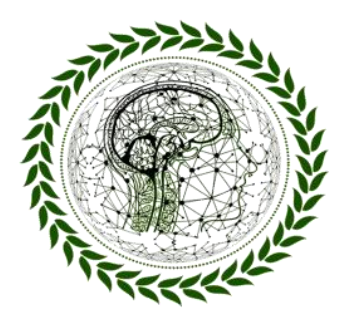

\section{PhI Scientific Review \\ ISSN 2676 - 0444}

Especificamente para a eliminação da bactéria, a penicilina é a solução mais eficaz, pois esse antibiótico interfere na síntese da parede celular bacteriana; quanto à dosagem, recomendamse 20.000 a $40.000 \mathrm{UI} \backslash K G$ via intramuscular, a cada 48 h, por 20 dias (no total de dez aplicações) (AVANTE et al., 2016).

Para terapia de suporte, realiza-se a correção do equilíbrio hidroelétrico e energético, como o uso de soro fisiológico e soro vitaminado, até o animal voltar a comer sozinho. Utilizamse tranquilizantes (acepromazina, 0,5 mL para cada $100 \mathrm{~kg}$, uma vez ao dia), e essa aplicação atua nas dores musculares do animal, servindo como relaxante. Já a dosagem de soro antitetânico é variada, conforme experiências vividas, não havendo teoria ou métodos científicos para tal. Em geral, aplica-se $1 \mathrm{ml}$ (meio frasco de soro, uma vez ao dia durante trinta dias (AVANTE et al., 2016).

Ainda, pode ser eficaz uma combinação de diazepam $(0,01-0,4 \mathrm{mg} / \mathrm{kg})$ e xilazina $(0,5-1,0$ $\mathrm{mg} / \mathrm{kg}$, por via intravenosa ou intramuscular), em casos de cavalos refratários aos tranquilizantes da fenotiazina (RADOSTITS, 2007).

Silva et al. (2010) explicam que a administração da antitoxina tetânica (TAT), em doses mais baixas (entre 5.000 UI e 50.000 UI) são recomendadas, por via intravenosa, intramuscular ou subcutânea, pois a TAT não atravessa a barreira hematoencefálica e atua diretamente sobre as toxinas circulantes que ainda não estão associadas aos receptores. Com relação à via intratecal, atualmente, estudos se mostram inconclusivos, e a TAT por esta via restringe-se apenas à pesquisa.

Quanto à letalidade do tétano, que é muito elevada, Megid et al. (2015) advertem sobre a gravidade da doença, estando diretamente associada ao tempo de incubação. Desse modo, quanto menor o período de incubação, maior a letalidade dos animais acometidos, portanto, a gravidade do tétano é inversamente proporcional ao tempo de incubação.

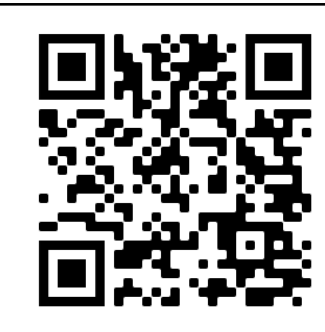

http://www.revistaphd.periodikos.com.br V. 01, N 07 , dezembro de 2021 DOI: $10.53497 /$ phdsr1n7-002 Todos os direitos reservados@ 


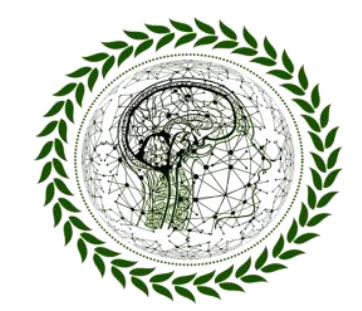

PhI Scientific Review

ISSN 2676 - 1444

\section{CONSIDERAÇÕES FINAIS}

Sendo assim, pode-se verificar que métodos de controle e medidas profiláticas podem reduzir significativamente o número de casos clínicos, bem como os prejuízos dos criadores em decorrência da possível morte do animal. Assim, recomendam-se cuidados especiais com os equinos, como, por exemplo, assistência veterinária, vacinação, higienização do local e dos instrumentos usados no manejo e em cirurgias.

\section{REFERÊNCIAS BIBLIOGRÁFICAS}

AVANTE, M. G.; OKADA, C. T.; ROMÃO, F. T. A. Tétano em um equino - relato de caso. 2016. 119 f. Tese (Doutorado) - Curso de Medicina Veterinária, Faculdade de Ensino Superior e Formação Integral, Garça - SP, 2016.

LIMA, J. T.; PATRÍCIO, L. A.; FARIAS, A. F. Tétano em equinos - relatos de casos. 2013. 214 f. Tese (Doutorado) - Curso de Medicina Veterinária, Universidade Rural de Pernambuco, Recife, 2013.

MAPA. Ministério da Agricultura, Pecuária e Abastecimento. Revisão do Estudo do Complexo do Agronegócio do Cavalo. Secretaria de Mobilidade Social, do Produtor Rural e do Cooperativismo. Brasília - DF, 2016.

MEGID, J.; RIBEIRO, M. G.; PAES, A. C. Doenças infecciosas em animais de produção e de companhia. Rio de Janeiro: Roca, 2015.

PEDROSO, A. C. B. R.; SOUSA, G. C.; NEVES, M. D. Tétano em potro atendido pelo serviço de controle sanitário e atendimento clínico-cirúrgico de cavalos carroceiros Hospital Veterinário. Disponível em: http://faef.revista.inf.br/imagens arquivos/arquivos destaque/1Da0q0dvIQULGxg_2013-813-18-32-14.pdf. Acesso em out. 2021. 


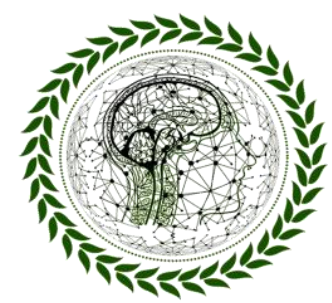

PhI Scientific Review

ISSN 2676 - 0444

PEREIRA, A. L. A. et al. Tétano em equino: relato de caso. Pubvet, v. 13, n. 6, a357, p.1-6, Jun., 2019.

RADOSTITS, O. M.; GAY, C. C.; HINCHCLIFF, K. W.; CONSTABLE, P. D. Veterinary Medicine: A textbook of the diseases of cattle, horses, sheep, pigs, and goats. 10th ed. SaundersElsevier, Philadelphia, 2007. 2156 p.

SILVA, A. A. et al. Uso de antitoxina tetânica por via intratecal e endovenosa no tratamento de tétano acidental em equino: relato de caso. Revista Científica Eletrônica De Medicina Veterinária, Ano VIII, n. 14, Jan., 2010.

ZAPPA, V.; FRANCISCO, L. S. Tétano em equinos - revisão de literatura. Revista FAEF.

Disponível em: http://faef.revista.inf.br/imagens arquivos/arquivos destaque/1Da0q0dvIQULGxg_2013-813-18-32-14.pdf. Acesso em out. 2021. 